\title{
Dopplerfluxometria da artéria femoral de cães adultos hígidos (Canis lupus familiaris)
}

\author{
Femoral Artery Dopplerfluxometry of Adult Healthy Dogs (Canis lupus familiaris) \\ Ivan Felismino Charas dos Santos', Letícia Rocha Inamassu'², Sheila Canevese Rahal', \\ Maria Jaqueline Mamprim³ , David José de Castro Martins², Bárbara Sardela Ferro ${ }^{4}$, Bruna Martins da Silva², \\ Gustavo Manea Ferreira², Marina Paiva Branco² \& José Ivaldo de Siqueira Silva Júnior ${ }^{2}$
}

\begin{abstract}
Background: In Veterinary Medicine, there are several methods for early and accurate assessment of blood flow dynamics. The Dopplerfluxometry can access the peak systolic velocity, mean velocity and end diastolic velocity, including Resistive Index and Pulsatility Index. Normal values of Dopplerfluxometry in healthy dogs allow the identification of vascular abnormalities and authors' knowledge there are no reference regarding the values of Dopplerfluxometry of the femoral artery in healthy dogs. The aim of the study was to assess the femoral Dopplerfluxometry of adult healthy dogs by Resistive Index, Pulsatility Index, systolic and diastolic velocities, and femoral artery diameter.

Materials, Methods \& Results: Eighteen healthy intact beagle dogs, male and female, aging from 2 to 4 years old (mean \pm SD: mean $3 \pm 0.8$ years), weighing from 10.1-17.9 kg [22.3-39.5 lb] [mean \pm SD: $14.3 \pm 2.7 \mathrm{~kg}(31.5 \pm 5.96 \mathrm{lb})]$ were used. The dogs underwent to physical examination, complete blood cell count, serum biochemistry examination urinalysis, and radiographs examination, muscular and cardiac evaluation. Females had to be in anestrous. All dogs were submitted to right femoral artery Dopplerfluxometry. The dogs were positioned in dorsal recumbency by one person without any chemical restraint. A high definition ultrasound device equipped with a $3-13 \mathrm{MHz}$ multi-frequency linear transducer was used. The right femoral artery was identified with the transducer positioned transversely on the right triangle femoral area. Peak systolic velocity, end-diastolic velocity was measured. The Resistivity Index and Pulsatility Index were calculated automatically by the ultrasound machine software. Three measurements were obtained with the Doppler spectrum. The values of peak systolic velocity, end-diastolic velocity, Resistivity Index, Pulsatility Index and femoral artery diameter were expressed as Mean \pm Standard Deviation (SD).

Discussion: No studies regarding to femoral artery Dopplerfluxometry in healthy dogs were found in the literature. These results can be used as normal reference values of Dopplerfluxometric parameters for adult dogs. The literature cited only Dopplerfluxometric values of renal arteries, abdominal aorta and of the internal thoracic artery. The normal values of arterial Dopplerfluxometry is necessary to identify the spectral quantitative characteristics of the blood flow for diagnosis and prognosis of vascular diseases. Authors referred to changes in blood perfusion by Dopplerfluxometry examination, but no changes in B-mode ultrasonography. The femoral Resistivity Index values can be used to correlate the postoperative evolution in dogs submitted to femoral bone, hip and knee surgeries, since Dopplerfluxometry allows blood flow assessment in the femoral region muscles. Changes in the heart rate, blood pressure, stress, exercise, and diseases as hypotension, renal lesion, hepatic diseases, diabetes, hyperadrenocorticism can change the Dopplerfluxometric parameters. All dogs which used in this study were clinically healthy, and were used beagle dogs due to lowest variations within breed. Sedation was avoid due to possible changes in Dopplerfluxometric parameters since the use of sedation or tranquilization in animals is strongly discussed due to possible hemodynamic changes that may occur during the examination. In conclusion, the mean values of the right femoral artery Dopplerfluxometry in male and female adult healthy dogs is Resistivity Index (0.887); Pulsatility Index (1.599); peak systolic velocity $(124.41 \mathrm{~cm} / \mathrm{s})$, end-diastolic velocity $(14.12 \mathrm{~cm} / \mathrm{s})$, femoral artery diameter $(3.9 \mathrm{~mm})$.
\end{abstract}

Keywords: resistivity index, pulsatility index, dopplerfluxometric parameters, small animals, hip dysplasia.

Descritores: índice de resistividade, índice de pulsatilidade, parâmetros dopplerfluxométricos, pequenos animais, displasia coxofemoral.

${ }^{1}$ Setor de Cirurgia Animal, Departamento de Cirurgia e Anestesiologia Veterinária (DCAV), ²Programa de Pós-graduação em Biotecnologia Animal, ${ }^{3}$ Setor de Diagnóstico por Imagem, Departamento de Radiologia Veterinária e Reprodução Animal (DRVRA) \& ${ }^{4}$ Programa de Pós-graduação em Animais Selvagens, Universidade Estadual Paulista (UNESP), Faculdade de Medicina Veterinária e Zootecnia (FMVZ), Botucatu, SP, Brazil. CORRESPONDENCE: I.F.C. Santos [ivansantos7 @ hotmail.com - Tel.: +55 (14) 3880-2022]. Setor de Cirurgia Animal, FMVZ - UNESP. Distrito de Rubião Junior s/n. CEP 18618-681 Botucatu, SP, Brazil. 


\section{INTRODUCTION}

Dopplerfluxometry quantified and qualified the hemodynamics assessing the blood flow, peak systolic velocity, mean velocity and end diastolic velocity, including the Resistive Index and Pulsatility Index $[1,5,15]$. The ultrasound technique of pulsed wave Doppler allows identifying the characteristics of blood flow and is a complementary technique for the two-dimensional ultrasonography, providing the hemodynamic characteristics, vascular anatomy and vascular morphology $[6,15]$.

The Resistive Index (RI) is a dimensionless value that determines the resistance of the vascular wall [14-15]. It is determined by the subtraction between peak systolic velocities (PSV) and end diastolic velocity (EDV) divided by the PSV [3,5,15]. The Pulsatility Index (PI) is used when the final diastolic flow tends to zero or in cases of negative blood flow, considering all the velocity of a cardiac cycle [11]. It is derived by the subtraction between PSV and EDV divided by the mean velocity (MV) [3,5,15]. Doppler indexes (RI and PI) provide information about vascular impedance, comparing the blood flow during systole and diastole $[11,15]$.

It is suggested that RI is inversely proportional to the metabolic rate, diastolic velocity and blood flow $[3,7,15]$.

Normal values of Dopplerfluxometry in healthy dogs allow the identification of vascular abnormalities, allowed to obtain reliable diagnostic and prognostic values [17]. Authors' knowledge there are no reference regarding the values of Dopplerfluxometry of the femoral artery in healthy dogs, the aim of the present study is to assess the femoral Dopplerfluxometry of adult healthy dogs by Resistive Index, Pulsatility Index, systolic and diastolic velocities, and femoral artery diameter.

\section{MATERIALS AND METHODS}

\section{Animals}

Eighteen healthy intact beagle dogs, nine males and nine females, aging from 2 to 4 years old (mean \pm SD: mean $3 \pm 0.8$ years), weighing from $10.1-17.9 \mathrm{~kg}$ [22.3-39.5 lb] [mean \pm SD: $14.3 \pm 2.7 \mathrm{~kg}(31.5 \pm 5.96 \mathrm{lb})]$ were used. The dogs underwent to physical examination, complete blood cell count (CBC), serum biochemistry examination (serum alanine aminotransferase - ALT, aspartate aminotransferase - AST, creatine kinase - CK, plasma creatinine - $\mathrm{CP}$, total serum protein - PT and albumin - Alb) and urinalysis (specific density, proteins, glucose, nitrite, bilirubin, ketone bodies, leukocytes, blood and urobilinogen and urinary $\mathrm{pH}$, quantification of epithelial cells, crystals, leukocytes, red blood cells, bacteria, mucus filaments and cylinders). Radiographs of the forelimb and hind limb joints were taken and muscular and cardiac evaluation was done. Dogs were considered healthy based on the results of these exams.

Exclusion criteria were history of surgical procedures or medication therapy applied 24 months before the experiment. Females had to be in anestrous and vaginal cytology was used to determine estrus stage of the females.

\section{Doppler ultrasonography procedures}

All dogs were submitted to right femoral artery Dopplerfluxometry (FAD), at 8 o'clock am, and always by the same operator. The medial femoral region of the right hind limb clipped one day before the dopplerfluxometry evaluations. Physical activity was not allowed for $12 \mathrm{~h}$ before the evaluations. Dogs were allowed to rest and acclimatize to the room for $2 \mathrm{~h}$ before the evaluation. The dopplerfluxometry exams were performed in room with temperature of $22^{\circ} \mathrm{C}$ and relative humidity between $40-45 \%$, controlled by thermo-hygrometer. Only three people remained in the room. Dogs were submitted to fasting for $1 \mathrm{~h}$ prior to FAD evaluation.

The dogs were positioned in dorsal recumbency by one person without any chemical restraint. A high definition ultrasound device $\left(\mathrm{My} \mathrm{Lab}^{\mathrm{TM}} 30 \mathrm{Vet}^{\circledR}\right)^{1}$ equipped with a 3 - $13 \mathrm{MHz}$ multi-frequency linear transducer was used. Acoustic gel was applied on the skin in the right triangle femoral area and the right femoral artery was identified with the transducer positioned transversely (Figure 1), using the Triplex Doppler. Peak systolic velocity (PSV), end-diastolic velocity (EDV) and RI was measured. The RI and PI were calculated automatically by the ultrasound machine software (Figure 2). Three measurements repetitions were obtained, with the Doppler spectrum containing at least three consecutive waveforms. Dopplerfluxometry examination was timed using a precision digital timer (Western $\left.\mathrm{Cr} 53^{\circledR}\right)^{2}$.

\section{Statistical analysis}

The values of RI, PI, PSV, EDV and femoral artery diameter (FAD) for each animal were expressed as Mean \pm Standard Deviation (SD). All data was recorded in an Excel $^{\circledR}$ worksheet for later evaluation. 


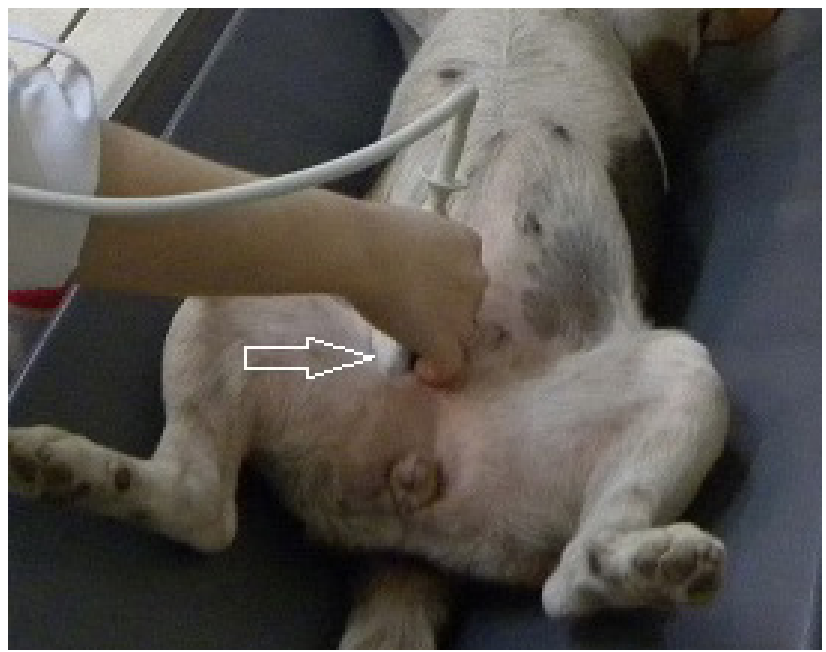

Figure 1. Dog on dorsal recumbency during the dopplerfluxometry of the right femoral artery [white arrow].

\section{RESULTS}

All dogs allowed femoral artery Dopplerfluxometry examination only with the physical restraint and performed by one person people. The FAD time was $2.1 \pm 0.8 \mathrm{~min}$. Body lengths and body height were $39.7 \pm 3.6 \mathrm{~cm}$ and $39.8 \pm 2.8 \mathrm{~cm}$, respectively. The RI, PI, PSV, EDV and FAD are described in Table 1.

Table 1. Mean and Standard Deviation (SD) of Resistive Index (RI), Pulsatility Index (PI), peak systolic velocities (PSV), end diastolic velocity (EDV) and femoral artery diameter (FAD) of the right femoral artery of 18 adult healthy dogs.

\begin{tabular}{cc}
\hline Parameter & Mean \pm SD \\
\hline Resistive Index $(\mathrm{RI})$ & $0.887 \pm 0.0181$ \\
Pulsatility Index $(\mathrm{PI})$ & $1.5996 \pm 0.057$ \\
Peak systolic velocities $(\mathrm{PSV})(\mathrm{cm} / \mathrm{s})$ & $124.41 \pm 1.59$ \\
End diastolic velocity $(\mathrm{EDV})(\mathrm{cm} / \mathrm{s})$ & $14.12 \pm 2.24$ \\
Femoral artery diameter $(\mathrm{FAD})(\mathrm{mm})$ & $3.9 \pm 0.33$ \\
\hline
\end{tabular}

\section{DISCUSSION}

No studies regarding to femoral artery Dopplerfluxometry in healthy dogs were found in the literature. The results of the present study can be used as normal reference values of Dopplerfluxometry for adult dogs. The literature cited only Dopplerfluxometric values of renal arteries [10], Dopplerfluxometric values of abdominal aorta and its main branches [9], and of the internal thoracic artery [2].

Normal values of arterial Dopplerfluxometry is essential to identify the spectral quantitative char-

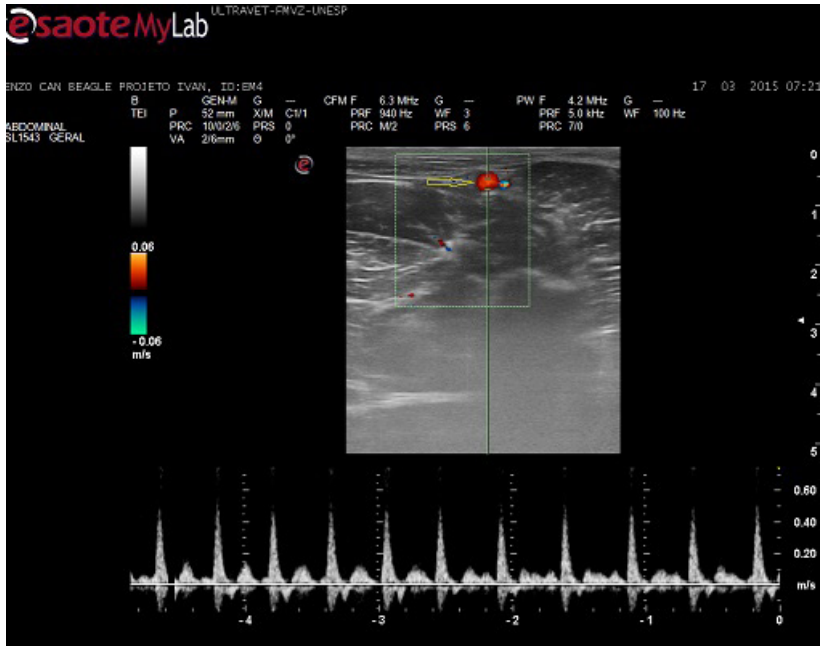

Figure 2. Ultrasonography image of dopplerfluxometry of the right femoral artery (Triplex Doppler mode) [yellow arrow].

acteristics of the blood flow, seeing as it is specific for each artery [15]. Studies based on normal vascular parameters are essential for diagnosis and prognosis of vascular diseases, allowing the examiner detects possible vascular changes such as peripheral hypertension, obstructive processes and acute vascular diseases. A study demonstrated that Dopplerfluxometry technique was relevant compared with B-mode ultrasonography in early evaluation of vascular diseases [10].

Femoral artery Dopplerfluxometry study through RI values can be used to correlate the postoperative evolution in dogs submitted to femoral bone, hip and knee surgeries. Dopplerfluxometry allows blood flow assessment in the femoral region muscles and the artery is the main and the most superficial artery that can be accessed by ultrasound $[3,15]$.

Dopplerfluxometry is a routine noninvasive examination that can be used at any age, requiring no contrast or ionizing radiation or anesthesia [8]. It is considered easy to perform but it requires experience and an adequate technique to obtain reliable parameters $[4,12]$. In the present study, all examinations were performed by one experienced operator, which allowed an adequate interpretation of the images. Although FAD is not a routine exam in clinical practice, in the present study the time to perform the exams was $2.1 \pm 0.8 \mathrm{~min}$, and was considered acceptable.

Changes in the heart rate, blood pressure, stress, exercise, are factors which can change RI [11]. On the other hand, diseases like hypotension, renal lesion, hepatic diseases, diabetes, hyperadrenocorticism, 
sedatives, anesthetics and cardiovascular medications also can change the RI values $[3,10,11,16]$. All dogs which used in this study were clinically healthy and no changes were observed in previous exams, and were used beagle dogs due to lowest variations within breed.

Linear transducer was used in the present study due to higher frequency and better definition of surface structures. On the other hand, normal Dopplerfluxometric values of the renal arteries of 20 medium-sized adult dogs were performed using a bifrequencial ( 5 to $7.5 \mathrm{MHz}$ ) sectorial transducer [10].

The use of sedative or tranquilizing drugs to perform the Dopplerfluxometry in animals is strongly discussed due to possible hemodynamic changes that may occur during the examination [5]. In the present study, the FAD was evaluated without using any sedative drugs in order to avoid possible changes in Dopplerfluxometric parameters [5]. Study with sedated healthy cats demonstrated any statistical difference between RI values in renal arcuate arteries [13]. In adult healthy dogs sedated with acepromazine $\left(0.03 \mathrm{mg} . \mathrm{kg}^{-1}\right)$ $10 \mathrm{~min}$ before the dopplerfluxometry examination were observed that the sedation protocol did not produce significant effects on heart and respiratory rates, and it is supposed that the difference in Dopplerfluxometry values was associated with the renal arterial branch assessed or the characteristics of the group of animals evaluated. If the sedation was needed in order to reduce the possible effects of stress, the lowest effective dose should be administered in order to minimize the vasoactive effects [10].

The Dopplerfluxometry of the internal thoracic artery in 10 adult dogs anesthetized with and without continuous intravenous norepinephrine administration verified that the mean diameter of the thoracic artery was $3.54 \mathrm{~mm}$ before norepinephrine infusion [2]. The diameter was smaller than the mean diameter values obtained in the present study on the right femoral artery $(3.90 \mathrm{~mm})$.

Study that evaluated the abdominal aorta and external iliac arteries biometry and hemodynamics of 131 clinically normal adult dogs identified a mean diameter (MD) of $8.0 \mathrm{~mm}$ and mean PSV of 104.0 cm.s-1 in the diaphragmatic segment of the abdominal aorta and a MD of $4.1 \mathrm{~mm}$ and $99.51 \mathrm{~cm} \cdot \mathrm{s}^{-1}$ of PSV for external iliac artery [9]. The MD of the aorta and the external iliac arteries were larger than the FAD of the present study.

\section{CONCLUSION}

In conclusion, the mean values of the right femoral artery Dopplerfluxometry in male and female adult healthy dogs is $\mathrm{RI}=0.887$; $\mathrm{PI}=1.599$; $\mathrm{PSV}=$ $124.41 \mathrm{~cm} . \mathrm{s}^{-1} ; \mathrm{EDV}=14.12 \mathrm{~cm} \cdot \mathrm{s}^{-1}$ and $\mathrm{FAD}=3.9 \mathrm{~mm}$. The femoral artery Dopplerfluxometric parameters in adult healthy dogs are easy to perform even without sedation. Authors' knowledge there is no reference regarding the values of Dopplerfluxometry of the femoral artery in healthy dogs.

\section{MANUFACTURERS \\ ${ }^{1}$ Esaote Group. Genova, Itália. \\ ${ }^{2}$ Vitoria Esportes - Atacado de Jogos. Canoas, RS, Brazil.}

Ethical approval. This experiment was approved and performed under the guidelines of the Ethics Committee in Animal Experimentation of the Faculty of Veterinary Medicine and Animal Science (FMVZ) of UNESP - São Paulo State University, Botucatu, São Paulo, under protocol nº 0138/2018.

Declaration of interest. The authors report no conflicts of interest. The authors alone are responsible for the content and writing of the paper.

\section{REFERENCES}

1 Akihiro K., Yutaka Y., Osamu U., Kazumi K., Jintetsu S. \& Tsuneharu M. 2001. Evaluation of reflux kidney using renal resistive index. Journal of Urology. 165: 2010-2012.

2 Bordinhão A. 2013. Comparação entre a Dopplermetria e o fluxo livre da artéria torácica interna de cães com e sem o uso de noradrenalina. Revista Brasileira de Cirurgia Cardiovascular. 28(2): 224-230.

3 Carvalho C.F. 2009. Ultrassonografia Doppler em pequenos animais. São Paulo: Roca, pp.71-83.

4 Carvalho C.F. \& Addad C.A. 2009. Interpretação da imagem Doppler. In: Carvalho C.F. (Ed). Ultrassonografia Doppler em pequenos animais. São Paulo: Roca, pp.15-19.

5 Cerri G.G., Mólnar L.J. \& Vezozzo D.C.P. 1996. Doppler. São Paulo: Sarvier, 271p.

6 Cerri G.C. \& Rocha D.C. 1993. Ultra-sonografia abdominal. São Paulo: Sarvier, 459p.

7 D'Anjou M., Bévard A. \& Dunn M.E. 2011. Clinical significance of renal pelvic dilatation on ultrasound in dogs and cats. Veterinary Radiology \& Ultrasound. 52: 88-94. 
8 Ferner M. 1994. Instrumentos doppler. Revista Brasileira De Ultrassonografia. 1(5): 6-10.

9 Kamikawa L. \& Bombonato P.P. 2007. Ultrassonografia da aorta abdominal e de seus ramos em cães. Ciência Rural. 37(2): 412-417.

10 Melo M.B., Veado J.C.C., Silva E.F., Moreira S.M. \& Passos L.M.F. 2006. Dopplerfluxometria das artérias renais: valores normais das velocidades sistólica e diastólica e do índice resistividade nas artérias renais principais. Arquivo Brasileiro de Medicina Veterinária e Zootecnia. 58(4): 691-693.

11 Novellas R., Espada Y. \& Ruiz De Gopegui R. 2007. Doppler ultrasonographic estimation of renal and ocular resistive and pulsatility indices in normal dogs and cats. Veterinary Radiology \& Ultrasound. 48(1): 69-73.

12 Platt J.F. 1997. Doppler ultrasound of the kidney. Seminars in Ultrasound, CT and MRI. 18(1): 22-32.

13 Rivers B.J., Walter P.A., O'brien T.D. \& Polzin D.J. 1996. Duplex Doppler estimation of Pourcelot Resistive Index in arcuate arteries of sedated normal cats. Journal of Veterinary Internal Medicine.10: 28-33.

14 Shokeir A.A., Shoma A.M., Abubieh E.A., Nasser M.A., Eassa W. \& El-Asmy A. 2002. Recoverability of renal function after relief of acute complete ureteral obstruction: clinical prospective study of the role of renal resistive index. Journal of Urology. 59(4): 506-510.

15 Szatmári V., Sotonyi P. \& Vörös K. 2001. Normal duplex Doppler waveforms of major blood vessels in dogs: a review. Veterinary Radiology \& Ultrasound. 42(42): 93-107.

16 Torroja R.N. 2007. Vascular resistance determination with Doppler ultrasound in canine and feline disease. 171p. Bellaterra, Barcelona. Dissertação (Doutorado em Veterinária - Medicina i Cirurgia Animals), Universitat Autònoma de Barcelona.

17 Valentini S., Migliorini F. \& Fedrigo M. 1996. Analisi ecografica di alcuni parametri fisiologici dell’aorta addominale del cane. Revista Clínica Veterinária. 10(3): 53-57. 